\title{
Association between pain sensitivity in the hand and outcomes after surgery in patients with lumbar disc herniation or spinal stenosis
}

\author{
Yvonne Lindbäck ${ }^{1}$ (D) Hans Tropp ${ }^{2} \cdot$ Paul Enthoven $^{1} \cdot$ Björn Gerdle $^{3} \cdot$ \\ Allan Abbott ${ }^{1,4} \cdot$ Birgitta Öberg $^{1}$
}

Received: 22 November 2016/Accepted: 24 January 2017/Published online: 6 February 2017

(c) The Author(s) 2017. This article is published with open access at Springerlink.com

\begin{abstract}
Purpose To investigate the association between pain sensitivity in the hand pre-surgery, and patient-reported outcomes (PROs) in function, pain and health pre- and postsurgery in patients with disc herniation or spinal stenosis. Methods This is a prospective cohort study with 82 patients. Associations between pressure-, cold- and heat pain threshold (PPT, CPT, HPT) in the hand pre-surgery and Oswestry, VAS pain, EQ-5D, HADS, and Self-Efficacy Scale, pre- and three months post-surgery; were investigated with linear regression.
\end{abstract}

Yvonne Lindbäck

yvonne.lindback@liu.se

Hans Tropp

hans.tropp@regionostergotland.se

Paul Enthoven

paul.enthoven@liu.se

Björn Gerdle

bjorn.gerdle@liu.se

Allan Abbott

allan.abbott@liu.se

Birgitta Öberg

birgitta.oberg@liu.se

1 Department of Medical and Health Sciences, Division of Physiotherapy, Faculty of Medicine and Health Sciences, Linköping University, SE-581 83 Linköping, Sweden

2 Department of Spinal Surgery and Department of Clinical and Experimental Medicine, Linköping University, Linköping, Sweden

3 Pain and Rehabilitation Centre and Department of Medical and Health Sciences, Linköping University, Linköping, Sweden

4 Faculty of Health Science and Medicine, Bond University, Gold Coast, QLD 4229, Australia
Results Patients with disc herniation more sensitive to pressure pain pre-surgery showed lower function and selfefficacy, and higher anxiety and depression pre-surgery, and lower function, and self-efficacy, and higher pain postsurgery. Results for cold pain were similar. In patients with spinal stenosis few associations with PROs were found and none for HPT and PROs.

Conclusions Altered pain response in pressure- and cold pain in the hand, as a sign of widespread pain pre-surgery had associations with higher pain, lower function and selfefficacy post-surgery in patients with disc herniation.

Keywords Disc herniation - Spinal stenosis - Spinal surgery · Widespread pain · Quantitative sensory testing

\section{Introduction}

Low back pain (LBP) is the condition causing most disability globally [1]. Only about $10 \%$ of all LBP problems are represented by disc herniation or spinal stenosis but they represent the most common conditions in spinal surgery $[2,3]$. In these groups, the outcome is questioned since $20-35 \%$ is doubtful or dissatisfied with the results at one-year follow-up [3]. Challenges are to develop screening identifying those with increased risk of a poor prognosis and to select interventions based on prognostic factors for improvement of outcomes [2, 4]. Socio-demographic, clinical, work-related and psychological risk factors may partly explain poor outcomes after spinal surgery [5]. Another reported risk factor is insufficient pain treatment pre- and post-surgery [6]. It has been suggested that screening of somatosensory function may contribute to the understanding of pain mechanisms involved [7]. Somatosensory profiles can be assessed with quantitative 
sensory testing (QST), by measuring amongst others pressure-, cold- and heat pain thresholds (PPT, CPT and HPT). Lowered pain thresholds in QST measurement is described as an indication for central hyperexcitability [8]. This alteration in sensory thresholds can either be localized or widespread including a non-affected body regions [9].

Thermal thresholds in an affected body region were normalized in patients with spinal degenerative disease, who had recovered 6 months post-surgery, while they were not normalized in patients with remaining pain post-surgery [10]. Lowered PPT in non-affected body regions was associated with higher pre-surgery and 12 months post-surgery pain severity, but not with change in pain from pre-surgery to follow-up after hip- or knee replacement [11]. A previous analysis of the present cohort of patients with degenerative lumbar spine disorders selected for surgery showed that an altered sensory profile in both affected and non-affected body regions pre-surgery were associated with higher backand leg pain intensity and lower mental health pre-surgery (Lindbäck Y et al. submitted manuscript 2016). However, prospective studies are needed to further examine whether these dimensions can be useful as a screening tool for outcome post-surgery. The purpose was to investigate the association between pain sensitivity in the hand pre-surgery, and patient-reported outcomes (PROs) in function, pain, and health pre- and post-surgery in patients with disc herniation or spinal stenosis. Our hypothesis was that patients more sensitive to pain in the hand, a sign of widespread altered pain response, will have higher pain, lower function, and health pre- and post-surgery.

\section{Method}

\section{Study design}

This is a prospective cohort study. The study conforms to the STROBE statement checklist. The study was approved by the Regional Ethics committee (Dnr 2013/410-31). The patients received oral and written information about the study and they all signed an informed consent before the measurement. Forty-seven patients (57\%) were even included in Prepare, a study investigating the effect of presurgery physiotherapy (Clintrials.gov: NCT02454400).

\section{Setting}

The patients were consecutively recruited at the University Spine Clinic, Linkoping, Sweden, between September 2013 and December 2014. The somatosensory function was investigated with QST 1-2 weeks pre-surgery by one single investigator at the Spine Clinic. The patients filled out PROs pre- and 3 months post-surgery.

\section{Participants}

The inclusion criteria were: age $25-80$ years; the presence of leg pain with or without back pain due to lumbar disc herniation or lumbar spinal stenosis, diagnosis confirmed by magnetic resonance imaging; failure of conservative intervention (without further specification) and pain level high enough to indicate surgical intervention (discectomy or decompression surgery with or without fusion).

\section{Variables}

A standardized QST protocol was used [12]. During QST, the patients were sitting comfortably in a quiet room with an air temperature of $22{ }^{\circ} \mathrm{C}$. Cold and heat pain threshold (CPT and HPT) were measured by a thermic stimulator (Somedic, Hörby, Sverige). A thermode containing a peltier element was used with a stimulating area of $25 \times 50 \mathrm{~mm}$. The baseline temperature was $+32{ }^{\circ} \mathrm{C}$ and for the thermal measures the temperature decreased or increased with $1{ }^{\circ} \mathrm{C} / \mathrm{s}$ within a range of +10 and $+50{ }^{\circ} \mathrm{C}$. The thermode was held on the dominant hand on the thenar eminence muscle. The instruction was to push the stop button when the cold/heat sensation was perceived as painful.

PPT was measured with a handheld electrical pressure algometer (Somedic, Hörby, Sweden). The pressure was applied at a rate of $30 \mathrm{kPa} / \mathrm{s}$, with a $1 \mathrm{~cm}$ diameter probe. The maximal pressure was $700 \mathrm{kPa}$ and at that point the applied pressure was released. The patient was instructed to tell when the pressure on the hand started to become painful and at that point the applied pressure would release.

The dependent variables were the patient-reported measures pre- and post-surgery: Oswestry disability index (ODI) [13], back and leg pain intensity (VAS) [14], Healthrelated quality of life (EQ-5D) [15], Hospital Anxiety and Depression Scale (HADS) [16], and Self-Efficacy Scale (SES) [17]. The independent variables were PPT, CPT and HPT pre-surgery.

\section{Statistical methods}

Statistical analysis was performed using IBM SPSS statistics version 23 . The level of significance was set to 0.05 . Patient demographics were presented as mean and standard deviation (SD) or numbers and frequencies. For between-group comparisons the unpaired Student's $t$ test, Mann-Whitney U test or the Chi-square test were used. To assess normal distribution and outliers KolmogorovSmirnov, Shapiro-Wilk, skewness, kurtosis, and plots for observed value and expected or deviation from normal, respectively, was used for each variable. Some variables were deviant, but judged as sufficient in visual assessment. 
Linear regression was used to analyze the associations between pain thresholds (independent variables) and patient-reported measures (dependent variables). All models were adjusted for age and gender. To assure adequate sample size, each analysis had a cases-to-independent variables ratio of about ten cases for every independent variable in the model. Missing data were few, and imputation was not used for missing data.

\section{Results}

\section{Descriptive data}

Patients with spinal stenosis $(n=53)$ were older and had more frequently a pain duration of more than 1 year than patients with disc herniation $(n=29)$ (Table 1$)$. There were no significant differences between the patient groups in gender distribution or in the pre- and post-surgery PROs (Table 1). On group level, there were no signs of anxiety or depression; on an individual level, there were eight patients with signs of anxiety and four patients with signs of depression according to HADS.

\section{Lumbar disc herniation}

PPT pre-surgery versus patient-reported measures preand post-surgery

In patients with disc herniation, a negative association existed between PPT and ODI pre-surgery $(P=0.006)$ (Table 2). Such negative association also existed between PPT and the two subscales of HADS pre-surgery (anxiety and depression) $(P=0.043$ and $P=<0.001$, respectively) and positively with SES pre-surgery $(P=0.017)$.

A negative association also existed between PPT presurgery and ODI post-surgery $(P=0.020)$ (Table 2). Furthermore, PPT pre-surgery was negatively associated with pain intensity in the leg post-surgery $(P=0.036)$ and positively with self-efficacy (SES) post-surgery $(P \leq 0.001)$.
Table 1 Demographic characteristics and self-reported function, pain and health of patients with disc herniation $(n=29)$ and spinal stenosis $(n=53)$, respectively at preand post-surgery

\begin{tabular}{lccc}
\hline & Disc herniation & Spinal stenosis & $p$ value \\
\hline Age, mean (SD) & $48.2(11.3)$ & $67.8(7.4)$ & $<0.001^{*}$ \\
Women, $n$ (\%) & $15(51.7)$ & $27(50.9)$ & 0.946 \\
Pain duration back/leg $>$ 1 years, $n(\%)$ & $11(40.7)$ & $41(77.4)$ & $0.001^{*}$ \\
Pre-surgery & & & \\
ODI, mean (SD) & $40.2(16.0)$ & $38.0(14.7)$ & 0.550 \\
VAS back pain last week, mean (SD) & $46.5(28.3)$ & $49.6(24.1)$ & 0.608 \\
VAS leg pain last week, mean (SD) & $60.2(21.2)$ & $54.8(23.9)$ & 0.308 \\
EQ-5D index, mean (SD) & $0.41(0.29)$ & $0.42(0.32)$ & 0.842 \\
EQ-VAS, mean (SD) & $50.7(22.0)$ & $51.2(22.1)$ & 0.923 \\
HADS anxiety, mean (SD) & $5.9(4.1)$ & $5.6(3.4)$ & 0.720 \\
HADS depression, mean (SD) & $4.5(3.5)$ & $4.3(3.1)$ & 0.729 \\
SES, mean (SD) & $125.1(43.9)$ & $133.2(39.7)$ & 0.421 \\
3 months post-surgery & & & \\
ODI, mean (SD) & $24.4(18.8)$ & $32.2(16.8)$ & 0.058 \\
VAS back pain last week, mean (SD) & $31.1(31.2)$ & $32.6(23.1)$ & 0.798 \\
VAS leg pain last week, mean (SD) & $27.3(31.5)$ & $28.6(27.4)$ & 0.845 \\
EQ-5D index, mean (SD) & $0.68(0.26)$ & $0.61(0.26)$ & 0.171 \\
EQ-VAS, mean (SD) & $71.7(20.9)$ & $65.6(22.7)$ & 0.241 \\
HADS anxiety, mean (SD) & $4.8(3.4)$ & $4.5(3.5)$ & 0.749 \\
HADS depression, mean (SD) & $3.1(3.0)$ & $3.6(2.8)$ & 0.445 \\
SES, mean (SD) & $153.6(39.5)$ & $151.6(34.5)$ & 0.822 \\
\hline
\end{tabular}

Missing data in disc herniation group; $\leq 2$ in all variables and in spinal stenosis group; $\leq 1$, except in SES pre- and post-surgery and HADS anxiety post-surgery were missing data was 4-9

SD, standard deviation; ODI, Oswestry Disability Index (0-100) (higher score indicates higher disability); VAS, Visual Analog Scale (0-100) (higher score indicates higher pain intensity); EQ-5D, EuroQol (-0.594 to 1) (higher score indicates better health); HADS, Hospital Anxiety and Depression Scale (0-21) (higher score indicates more signs of symptoms); SES, Self-Efficacy Scale (0-200) (higher score indicates better self-efficacy). *denotes significance 


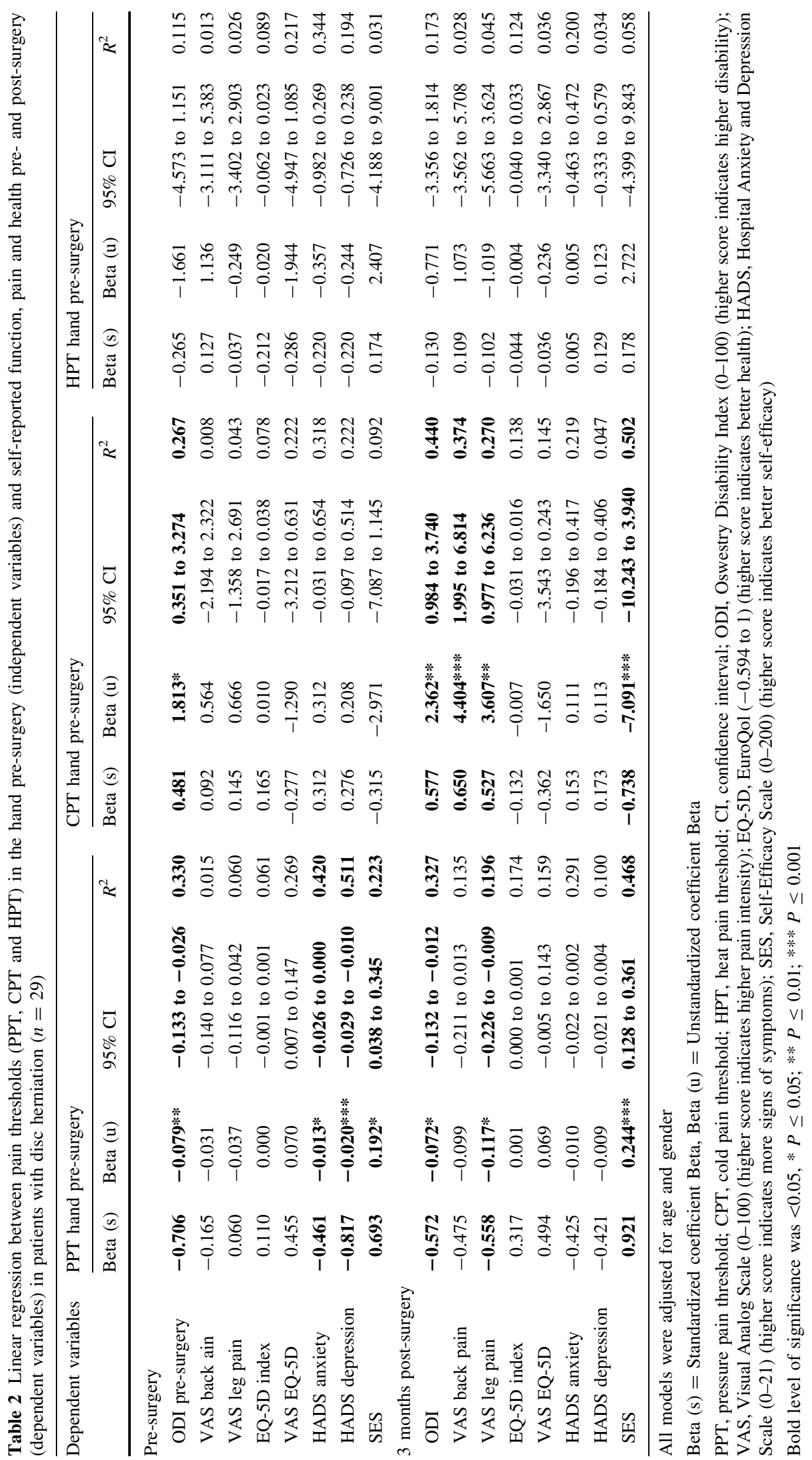


CPT pre-surgery versus patient-reported measures preand post-surgery

In patients with disc herniation there was a positive association between CPT pre-surgery and ODI pre-surgery $(P=0.017)$ (Table 2). Furthermore, there were also positive correlations between CPT pre-surgery and ODI postsurgery $(P=0.002)$ and higher back pain and leg pain in VAS post-surgery $(P=0.001$ and $P=0.009$, respectively). Furthermore, a negative association between CPT pre-surgery and self-efficacy (SES) post-surgery $(P<0.001)$ also existed.

\section{HPT pre-surgery versus patient-reported measures pre- and post-surgery}

There were no associations between HPT pre-surgery and patient-reported measures pre- and post-surgery (Table 2).

\section{Lumbar spinal stenosis}

\section{PPT pre-surgery versus patient-reported measures pre- and post-surgery}

In patients with spinal stenosis, there were no significant associations between PPT and the pre-surgery patient-reported measures (Table 3). A negative association existed between PPT pre-surgery and HADS (anxiety) post-surgery $(P=0.001)$.

\section{CPT pre-surgery versus patient-reported measures pre- and post-surgery}

There were positive correlations between CPT pre-surgery, and HADS (anxiety) $(P=0.014)$ pre- and also post-surgery $(P=0.025)$ (Table 3$)$.

\section{HPT pre-surgery versus patient-reported measure pre- and post-surgery}

There were no associations between HPT pre-surgery and patient-reported measures pre- nor post-surgery (Table 3).

\section{Discussion}

The results showed that patients with disc herniation in lumbar spine who were more sensitive to pressure pain in the hand pre-surgery had lower function, more signs of anxiety and depression, and lower self-efficacy pre-surgery. Prospectively, more sensitivity to pressure pain presurgery was associated with lower function, higher pain intensity and lower self-efficacy post-surgery. The pattern of associations was very similar for cold pain in this group of patients. Hence, our hypothesis that patients with sign of widespread altered pain response would have worse PROs pre- and post-surgery was mainly confirmed in patients with disc herniation. However, it was not confirmed in patients with spinal stenosis, since the only associations found were that patients who were more sensitive to cold pain had more signs of anxiety pre- and post-surgery, and those more sensitive to pressure pain had more signs of anxiety post-surgery. Another interesting result was that there were no associations between HPT and patient-reported measures in either of the diagnostic groups.

In a review of cross-sectional studies of patients with heterogeneous diagnoses of spinal pain, it was concluded that pain threshold had little or no correlation with disability and pain intensity [18]. In comparison, our study included homogenous groups of patients with specific diagnosis who also went through a decision making process for surgery. Our study is the first to report prospective results showing associations between high sensitivity to pressure and cold in a non-affected body region pre-surgery and lower function, higher pain intensity and lower selfefficacy post-surgery in patients with LBP. However, the results were only found in the disc herniation group. A possible reason for the different results for patients with disc herniation may be the presence of inflammation, which often causes more on-going nociceptive stimuli and constant pain experience that could cause more risk of plasticity changes in the nervous system [6]. In disc herniation, the sciatic pain is described to have both a neuropathic component with the mechanical-stimuli causing the nerve root compression and also an inflammatory component [19].

In the patients with disc herniation, PPT on the hand, as a screening tool for signs of widespread altered pain response in pain threshold, had associations with the PROs. PPT is supposed to measure deep pain and muscle sensitivity [20] and pressure pain hyperalgesia is sign of peripheral sensitization of C-fibers in tissue injury [20]. It has not yet been fully demonstrated that PPT captures central pain processing. Although in single studies hyperalgesia to pressure pain in a non-affected body region has been reported in non-specific LBP [21] and after hip- and knee replacement concluding that it might indicate central pain processing [11, 21].

PPT and CPT both measure A-delta and C-afferents, but with mechanical, respectively, thermal stimuli [7]. In this study, CPT had no associations with psychological factors pre-surgery, while lowered PPT was associated with more anxiety- and depression signs and lower self-efficacy. Further, more sensitivity to cold pain had an association with higher back pain intensity post-surgery; where PPT also had association to pain intensity but to leg pain. 
Table 3 Linear regression between pain thresholds (PPT, CPT and HPT) in the hand pre-surgery (independent variables) and self-reported function, pain and health pre- and post-surgery (dependent variables) in patients with spinal stenosis $(n=53)$

\begin{tabular}{|c|c|c|c|c|c|c|c|c|c|c|c|c|}
\hline \multirow{2}{*}{$\begin{array}{l}\text { Dependent } \\
\text { variables }\end{array}$} & \multicolumn{4}{|c|}{ PPT hand pre-surgery } & \multicolumn{4}{|c|}{ CPT hand pre-surgery } & \multicolumn{4}{|c|}{ HPT hand pre-surgery } \\
\hline & $\begin{array}{l}\text { Beta } \\
(\mathrm{s})\end{array}$ & Beta (u) & $95 \% \mathrm{CI}$ & $R^{2}$ & $\begin{array}{l}\text { Beta } \\
(\mathrm{s})\end{array}$ & Beta (u) & $95 \% \mathrm{CI}$ & $R^{2}$ & $\begin{array}{l}\text { Beta } \\
(s)\end{array}$ & $\begin{array}{l}\text { Beta } \\
\text { (u) }\end{array}$ & $95 \% \mathrm{CI}$ & $R^{2}$ \\
\hline \multicolumn{13}{|l|}{ Pre-surgery } \\
\hline ODI & 0.297 & 0.028 & $\begin{array}{c}-0.009 \text { to } \\
0.065\end{array}$ & 0.077 & 0.127 & 0.553 & $\begin{array}{c}-0.667 \text { to } \\
1.782\end{array}$ & 0.048 & 0.139 & 0.695 & $\begin{array}{c}-0.760 \text { to } \\
2.150\end{array}$ & 0.050 \\
\hline $\begin{array}{l}\text { VAS back } \\
\text { pain }\end{array}$ & -0.111 & 0.017 & $\begin{array}{l}-0.044 \text { to } \\
0.79\end{array}$ & 0.034 & 0.142 & 1.014 & $\begin{array}{l}-1.003 \text { to } \\
3.030\end{array}$ & 0.048 & 0.070 & 0.571 & $\begin{array}{l}-1.836 \text { to } \\
2.978\end{array}$ & 0.032 \\
\hline $\begin{array}{l}\text { VAS leg } \\
\text { pain }\end{array}$ & -0.157 & -0.024 & $\begin{array}{l}-0.084 \text { to } \\
0.036\end{array}$ & 0.057 & 0.185 & 1.309 & $\begin{array}{l}-0.657 \text { to } \\
3.276\end{array}$ & 0.078 & -0.034 & -0.278 & $\begin{array}{l}-2.648 \text { to } \\
2.092\end{array}$ & 0.045 \\
\hline $\begin{array}{r}\text { EQ-5D } \\
\text { index }\end{array}$ & -0.068 & 0.000 & $\begin{array}{c}-0.001 \text { to } \\
0.001\end{array}$ & 0.027 & -0.153 & -0.014 & $\begin{array}{c}-0.041 \text { to } \\
0.012\end{array}$ & 0.048 & -0.051 & -0.006 & $\begin{array}{l}-0.039 \text { to } \\
0.027\end{array}$ & 0.027 \\
\hline VAS EQ-5D & -0.270 & -0.038 & $\begin{array}{l}-0.094 \text { to } \\
0.017\end{array}$ & 0.068 & 0.005 & 0.031 & $\begin{array}{l}-1.832 \text { to } \\
1.895\end{array}$ & 0.031 & -0.105 & -0.790 & $\begin{array}{l}-2.985 \text { to } \\
1.405\end{array}$ & 0.042 \\
\hline $\begin{array}{l}\text { HADS } \\
\text { anxiety }\end{array}$ & -0.070 & -0.002 & $\begin{array}{l}-0.010 \text { to } \\
0.007\end{array}$ & 0.043 & 0.338 & $0.347 *$ & $\begin{array}{c}0.072 \text { to } \\
0.623\end{array}$ & 0.154 & -0.090 & -0.103 & $\begin{array}{l}-0.439 \text { to } \\
0.233\end{array}$ & 0.048 \\
\hline $\begin{array}{l}\text { HADS } \\
\text { depression }\end{array}$ & 0.058 & 0.001 & $\begin{array}{c}-0.007 \text { to } \\
0.009\end{array}$ & 0.022 & 0.008 & 0.007 & $\begin{array}{c}-0.266 \text { to } \\
0.281\end{array}$ & 0.020 & 0.180 & 0.190 & $\begin{array}{l}-0.119 \text { to } \\
0.500\end{array}$ & 0.050 \\
\hline SES & -0.167 & -0.043 & $\begin{array}{l}-0.161 \text { to } \\
0.075\end{array}$ & 0.038 & -0.083 & -1.016 & $\begin{array}{l}-4.907 \text { to } \\
2.875\end{array}$ & 0.031 & -0.096 & -1.353 & $\begin{array}{c}-5.967 \text { to } \\
3.261\end{array}$ & 0.033 \\
\hline \multicolumn{13}{|c|}{3 months post-surgery } \\
\hline ODI & -0.179 & -0.019 & $\begin{array}{c}-0.062 \text { to } \\
0.023\end{array}$ & 0.059 & 0.031 & 0.155 & $\begin{array}{l}-1.258 \text { to } \\
1.567\end{array}$ & 0.042 & 0.127 & 0.721 & $\begin{array}{c}-0.933 \text { to } \\
2.375\end{array}$ & 0.057 \\
\hline $\begin{array}{l}\text { VAS back } \\
\text { pain }\end{array}$ & 0.199 & 0.030 & $\begin{array}{c}-0.029 \text { to } \\
0.088\end{array}$ & 0.050 & -0.032 & -0.221 & $\begin{array}{c}-2.171 \text { to } \\
1.728\end{array}$ & 0.031 & 0.149 & 1.172 & $\begin{array}{l}-1.114 \text { to } \\
3.458\end{array}$ & 0.050 \\
\hline $\begin{array}{l}\text { VAS leg } \\
\text { pain }\end{array}$ & -0.086 & -0.015 & $\begin{array}{l}-0.086 \text { to } \\
0.055\end{array}$ & 0.020 & 0.118 & 0.960 & $\begin{array}{l}-1.352 \text { to } \\
3.271\end{array}$ & 0.030 & 0.071 & 0.661 & $\begin{array}{l}-2.090 \text { to } \\
3.412\end{array}$ & 0.021 \\
\hline $\begin{array}{r}\text { EQ-5D } \\
\text { index }\end{array}$ & 0.323 & 0.001 & $\begin{array}{c}0.000 \text { to } \\
0.001\end{array}$ & 0.118 & -0.212 & -0.016 & $\begin{array}{c}-0.038 \text { to } \\
0.005\end{array}$ & 0.110 & 0.236 & 0.021 & $\begin{array}{l}-0.004 \text { to } \\
0.046\end{array}$ & 0.117 \\
\hline VAS EQ-5D & 0.191 & 0.028 & $\begin{array}{l}-0.031 \text { to } \\
0.086\end{array}$ & 0.032 & 0.006 & 0.042 & $\begin{array}{l}-1.902 \text { to } \\
1.985\end{array}$ & 0.013 & -0.153 & -1.175 & $\begin{array}{c}3.443 \text { to } \\
1.092\end{array}$ & 0.035 \\
\hline $\begin{array}{l}\text { HADS } \\
\text { anxiety }\end{array}$ & -0.673 & $-0.015 * * *$ & $\begin{array}{l}-0.024 \text { to }- \\
0.006\end{array}$ & 0.216 & 0.327 & $0.330 *$ & $\begin{array}{c}0.043 \text { to } \\
0.617\end{array}$ & 0.114 & -0.245 & -0.284 & $\begin{array}{c}-0.640 \text { to } \\
0.072\end{array}$ & 0.063 \\
\hline $\begin{array}{l}\text { HADS } \\
\text { depression }\end{array}$ & -0.072 & -0.001 & $\begin{array}{l}-00.009 \text { to } \\
0.007\end{array}$ & 0.007 & 0.024 & 0.020 & $\begin{array}{l}-0.226 \text { to } \\
0.265\end{array}$ & 0.005 & 0.061 & 0.059 & $\begin{array}{c}-0.234 \text { to } \\
0.351\end{array}$ & 0.008 \\
\hline SES & -0.039 & -0.009 & $\begin{array}{c}-0.090 \text { to } \\
0.073\end{array}$ & 0.244 & -0.006 & -0.056 & $\begin{array}{c}-2.798 \text { to } \\
2.687\end{array}$ & 0.243 & -0.071 & -0.803 & $\begin{array}{c}-0.960 \text { to } \\
2.354\end{array}$ & 0.247 \\
\hline
\end{tabular}

All models were adjusted for age and gender

Beta $(\mathrm{s})=$ Standardized coefficient Beta, Beta $(\mathrm{u})=$ Unstandardized coefficient Beta

PPT, pressure pain threshold; CPT, cold pain threshold; HPT, heat pain threshold; CI, confidence interval; ODI, Oswestry Disability Index (0-100) (higher score indicates higher disability); VAS, Visual Analog Scale (0-100) (higher score indicates higher pain intensity); EQ-5D, EuroQol (- 0.594 - 1) (higher score indicates better health); HADS, Hospital Anxiety and Depression Scale (0-21) (higher score indicates more signs of symptoms); SES, Self-Efficacy Scale (0-200) (higher score indicates better self-efficacy)

Bold $=$ level of significance was $<0.05, * P \leq 0.05 ; * * P \leq 0.01 ; * * * P \leq 0.001$

Despite these smaller differences in PPT and CPT associations pre-surgery, this study showed that PPT and CPT mainly had similar associations with the post-surgery outcomes. PPT is the QST measure described as most sensitive for pain excitability in patients with osteoarthritis [22] as well as in chronic LBP [23]. While CPT in patients with whiplash-associated disorders (WAD) had moderate evidence to be a predictor for outcomes in pain and disability [24]. Our result support to further analyze PPT and CPT also in degenerative lumbar spine disorders scheduled for surgery, when more sensitivity for pressure- and cold pain in a non-affected body region pre-surgery were associated with lower function, higher pain intensity and lower self-efficacy post-surgery. 
The current study has its strengths and weaknesses. QST results can be influenced by psychological factors [12]. Our material was too small to adjust the regressions for possible confounding factors, e.g., psychological factors. Further, temporal summation or other dynamic QST could have been of interest, since these have been recommended to assess pain experience [7]. The difference in age between patients with disc herniation and spinal stenosis does probably not explain the differences in results since a strength of our study is that regression model was adjusted for age. Moreover, pain thresholds do not change with age [25]. Another strength of our study is that the regressions were adjusted for gender to handle the well-known sex differences in pain thresholds [20].

The results from this study should be interpreted with some caution since the study samples were relatively small. Despite this, we have compared the profile on patient-reported characteristics for the groups with the Swedish national spine register [3] and they have similar characteristics suggesting that results can be generalized to the larger Swedish population and potentially international populations with a similar health system context. Further larger prospective studies are needed to confirm our findings and be able to perform multivariate analyses. Prospective studies with validated outcomes were recently requested in a QST review concerning LBP [8]. With the associations found in this study, measuring PPT hand, a non-affected body region pre-surgery, might be a screening tool potentially capable of identifying patients with suboptimal functional outcome, e.g., ODI.

Barriers to use QST in clinical practice are that the measurements take long time and advanced equipment is required. Development of less time consuming QST protocols are needed [7]. The handheld electrical pressure algometer used for PPT measurement is more or less standard equipment and more feasible in Spine Clinics. To investigate only a non-affected body region for screening of widespread altered pain response can help to overcome barriers for clinical use and collection of larger patients' groups is needed to further analyze the value of PPT.

\section{Conclusion}

Measuring pressure pain threshold in a non-affected body region, as a sign for widespread altered pain response, showed that patients with lumbar disc herniation who were more sensitive to pressure pain in the hand pre-surgery had lower function, more signs of anxiety and depression and lower self-efficacy pre-surgery. Prospectively, more sensitivity to pressure pain pre-surgery was associated with lower function, higher pain intensity and lower self- efficacy post-surgery. The results for cold pain were similar except there were no associations with psychological variables pre-surgery. In patients with spinal stenosis, there was lack of associations. Based on the associations postsurgery, further analyses of PPT in the hand as a sign of widespread altered pain response pre-surgery in patients with disc herniation are suggested.

Acknowledgements We thank Maria Öberg, RPT, for performing the QST measurements in all participants.

\section{Compliance with ethical standards}

\section{Conflict of interest None.}

Funding The study received financial support from the Swedish Research Council (No 521-2019-3578), the Faculty of Medicine and Health, Linköping University, and the County Council of Östergötland, Linköping, Sweden. Association between pain sensitivity in the hand and outcomes after surgery in patients with lumbar disc herniation or spinal stenosis.

Open Access This article is distributed under the terms of the Creative Commons Attribution 4.0 International License (http://crea tivecommons.org/licenses/by/4.0/), which permits unrestricted use, distribution, and reproduction in any medium, provided you give appropriate credit to the original author(s) and the source, provide a link to the Creative Commons license, and indicate if changes were made.

\section{References}

1. Hoy D, March L, Brooks P, Blyth F, Woolf A, Bain C, Williams G, Smith E, Vos T, Barendregt J, Murray C, Burstein R, Buchbinder R (2014) The global burden of low back pain: estimates from the Global Burden of Disease 2010 study. Ann Rheum Dis 73:968-974. doi:10.1136/annrheumdis-2013-204428

2. Gibson JN, Waddell G (2007) Surgical interventions for lumbar disc prolapse: updated Cochrane Review. Spine 32:1735-1747. doi:10.1097/BRS.0b013e3180bc2431

3. Stromqvist B, Fritzell P, Hagg O, Jonsson B, Sanden B (2013) Swespine: the Swedish spine register: the 2012 report. Eur Spine J Off Publ Eur Spine Soc Eur Spinal Deform Soc Eur Sect Cerv Spine Res Soc 22:953-974. doi:10.1007/s00586-013-2758-9

4. Kreiner DS, Shaffer WO, Baisden JL, Gilbert TJ, Summers JT, Toton JF, Hwang SW, Mendel RC, Reitman CA (2013) An evidence-based clinical guideline for the diagnosis and treatment of degenerative lumbar spinal stenosis (update). Spine J Off J N Am Spine Soc 13:734-743. doi:10.1016/j.spinee.2012.11.059

5. den Boer JJ, Oostendorp RA, Beems T, Munneke M, Oerlemans M, Evers AW (2006) A systematic review of bio-psychosocial risk factors for an unfavourable outcome after lumbar disc surgery. Eur Spine J Off Publ Eur Spine Soc Eur Spinal Deform Soc Eur Sect Cerv Spine Res Soc 15:527-536. doi:10.1007/s00586005-0910-x

6. Reddi D (2016) Preventing chronic postoperative pain. Anaesthesia 71(Suppl 1):64-71. doi:10.1111/anae.13306

7. Cruz-Almeida Y, Fillingim RB (2014) Can quantitative sensory testing move us closer to mechanism-based pain management? Pain Med (Malden, Mass) 15:61-72. doi:10.1111/pme.12230

8. Marcuzzi A, Dean CM, Wrigley PJ, Chakiath RJ, Hush JM (2016) Prognostic value of quantitative sensory testing in low 
back pain: a systematic review of the literature. J Pain Res 9:599-607. doi:10.2147/jpr.s115659

9. Blumenstiel K, Gerhardt A, Rolke R, Bieber C, Tesarz J, Friederich HC, Eich W, Treede RD (2011) Quantitative sensory testing profiles in chronic back pain are distinct from those in fibromyalgia. Clin J Pain 27:682-690. doi:10.1097/AJP. 0b013e3182177654

10. Zub LW, Szymczyk M, Pokryszko-Dragan A, Bilinska M (2013) Evaluation of pain in patients with lumbar disc surgery using VAS scale and quantitative sensory testing. Adv Clin Exp Med Off Organ Wroclaw Med Univ 22:411-419

11. Wylde V, Sayers A, Lenguerrand E, Gooberman-Hill R, Pyke M, Beswick AD, Dieppe P, Blom AW (2015) Preoperative widespread pain sensitization and chronic pain after hip and knee replacement: a cohort analysis. Pain 156:47-54. doi:10.1016/j. pain.0000000000000002

12. Wallin M, Liedberg G, Borsbo B, Gerdle B (2012) Thermal detection and pain thresholds but not pressure pain thresholds are correlated with psychological factors in women with chronic whiplash-associated pain. Clin J Pain 28:211-221. doi:10.1097/ AJP.0b013e318226c3fd

13. Fairbank JC, Couper J, Davies JB, O'Brien JP (1980) The Oswestry low back pain disability questionnaire. Physiotherapy 66:271-273

14. Scott J, Huskisson EC (1976) Graphic representation of pain. Pain 2:175-184

15. Euro Qol Group (1990) EuroQol-a new facility for the measurement of health-related quality of life. Health Policy (Amsterdam, Netherlands) 16:199-208

16. Bjelland I, Dahl AA, Haug TT, Neckelmann D (2002) The validity of the hospital anxiety and depression scale. An updated literature review. J Psychosom Res 52:69-77

17. Altmaier E (1993) Role of self-efficacy in rehabilitation outcome among chronic low back pain patients. J Couns Psychol 40:335-339
18. Hubscher M, Moloney N, Leaver A, Rebbeck T, McAuley JH, Refshauge KM (2013) Relationship between quantitative sensory testing and pain or disability in people with spinal pain-a systematic review and meta-analysis. Pain 154:1497-1504. doi:10. 1016/j.pain.2013.05.031

19. Freynhagen R, Baron R (2009) The evaluation of neuropathic components in low back pain. Curr Pain Headache Rep 13:185-190

20. Rolke R, Andrews Campbell K, Magerl W, Treede RD (2005) Deep pain thresholds in the distal limbs of healthy human subjects. Eur J Pain (London, England) 9:39-48. doi:10.1016/j. ejpain.2004.04.001

21. Giesecke T, Gracely RH, Grant MA, Nachemson A, Petzke F, Williams DA, Clauw DJ (2004) Evidence of augmented central pain processing in idiopathic chronic low back pain. Arthritis Rheum 50:613-623. doi:10.1002/art.20063

22. Suokas AK, Walsh DA, McWilliams DF, Condon L, Moreton B, Wylde V, Arendt-Nielsen L, Zhang W (2012) Quantitative sensory testing in painful osteoarthritis: a systematic review and meta-analysis. Osteoarthr Cartil/OARS, Osteoarthr Res Soc 20:1075-1085. doi:10.1016/j.joca.2012.06.009

23. Neziri AY, Curatolo M, Limacher A, Nuesch E, Radanov B, Andersen OK, Arendt-Nielsen L, Juni P (2012) Ranking of parameters of pain hypersensitivity according to their discriminative ability in chronic low back pain. Pain 153:2083-2091. doi:10.1016/j.pain.2012.06.025

24. Goldsmith R, Wright C, Bell SF, Rushton A (2012) Cold hyperalgesia as a prognostic factor in whiplash associated disorders: a systematic review. Manual Therapy 17:402-410. doi:10. 1016/j.math.2012.02.014

25. Guergova S, Dufour A (2011) Thermal sensitivity in the elderly: a review. Ageing Res Rev 10:80-92. doi:10.1016/j.arr.2010.04. 009 